\title{
Mujer, migración intrarregional e invisibilidad
}

\section{Women, intraregional migration and invisibility}

\author{
Véronique Landry \\ Estudiante Magíster Universidad de Chile \\ veroniquelandry26@gmail.com
}

\begin{abstract}
SÍNTESIS
Se proyecta en este artículo relacionar la precariedad de los estudios académicos sobre las mujeres migrantes como nuevas sujetas con la invisibilidad y las vulnerabilidades padecidas por ellas en América Latina; eso, desde los conceptos simbólicos de "mujer" y "cuerpo".
\end{abstract}

\begin{abstract}
This article pretends to relate the precariousness of migration studies from a gender perspective within an academic setting with the invisibility and vulnerability suffered by women in Latin America; based on "woman" and "body" symbolic concepts.
\end{abstract}

Palabras claves: Migración, género, mujer, cuerpo, invisibilidad.

Keywords: Migration, Gender Studies, women, body, invisibility.

En el transcurso del tiempo, las mujeres latinoamericanas siempre han estado presentes en los procesos migratorios. Específicamente, como lo demuestra Martínez Pizarro (2003, 20), podemos afirmar que, al nivel regional, éstas representan en la actualidad casi la mitad de la población migrante en América Latina, llegando a 50.5\% en 2000, un aumento de $5.8 \%$ comparado con 1960, sea $44.7 \%{ }^{1}$. A pesar de esta evidencia, solo recientemente se ha introducido el aspecto de diferencial de sexo y la perspectiva de género desde una 
mirada regional al momento de analizar y estudiar los movimientos migratorios latinoamericanos. Esto a pesar de que la mujer latina ha participado activamente en estas corrientes y a que posee una experiencia migratoria propia. En la mayoría de las ocasiones, la no incorporación de la mujer dentro del flujo migratorio se debía a que ésta aparecía como aliada del hombre (pareja o esposo) cumpliendo el rol de acompañante más que de sujeta ${ }^{2}$.

Al momento de observar los estudios sobre la migración internacional anteriores a los años $80^{3}$, se reconoce en su mayoría teorías elaboradas desde la perspectiva de los países desarrollados (Europa, Estados Unidos). Estas insinuaban que el modelo representativo del sujeto migrante era de tipo económico y de sexo masculino, lo cual le daba a la mujer migrante un rol de simple acompañante, siguiendo un patrón "asociativo" o con un fin de reunificación familiar. De esta manera, para justificar la exclusión teórica, se fundamentaron las diferencias de roles desde las dicotomías tradicionales de producción/reproducción y masculino/ femenino. Como el sujeto migrante masculino representaba lo laboral y lo económico, es decir "lo productivo", toda la faceta migratoria estaba centrada en él. Estos estudios, se mantenían además, dentro de una visión y un ámbito neo-capitalista ${ }^{4}$. Se puede insinuar entonces que las mujeres migrantes, en los estudios anteriores a los 80, fueron invisibilizadas y silenciadas por su condición femenina y simbolizadas como "no-productivas económicamente" 5 .

Es en los años 80, cuando se produce cierto giro en lo que se refiere a la percepción de sexo y género sobre el migrante. Así mismo, y como contraposición a la postura androcéntrica anterior a estos años, se inició paulatinamente un nuevo marco conceptual dentro de la teoría migratoria internacional, lo que involucró un cierto cambio demostrativo que permitió a la mujer entrar desde lo académico como un nuevo sujeto incorporando el análisis de género para los fenómenos migratorios.

Se empezaron entonces a desarrollar varias conceptualizaciones desde el enfoque de género que permitieron tanto desmitificar a la mujer de su rol asociativo al migrante masculino como evidenciar teórica y conceptualmente el incremento de mujeres que migran de forma independiente. A esto, se inició paulatinamente, el análisis de la globalización y sus influencias sobre la heterogénea de los 
movimientos migratorios femeninos y su territorialidad ${ }^{6}$, todos elementos que serán revisado dentro de este artículo.

La meta de este artículo es entonces demostrar por una parte que, si bien los estudios académicos de después de los 80 empezaron a entender que la sujeta migrante representa una entidad distinta a la del sujeto migrante masculino, la incorporación analítica de la matriz género/intrarregional dentro del mecanismo investigativo, es aún precaria y pone de relieve un vacío innegable en los estudios migratorios desde dicho enfoque. A este respecto, uno de los temas más trascendentales que requiere un enfoque substancial de género, podría ser la invisibilidad y el silenciamiento de las latinoamericanas al personificar no solo a una sujeta migrante regional (sur-sur) sino también a una mujer. De esto se analizará la relación entre mujer latinoamericana, intrarregionalidad (sur-sur) e invisibilidad. Para eso, se apoyará en las propuestas filosóficas de Simone de Beauvoir (1949) y su concepto construccional de la "mujer", también se tomarán en cuenta los aportes de Marta Lama (1996) y su definición del término "género", así como el "acto performativo" de Judith Butler (1998) para argumentar el escaso énfasis hacia las mujeres migrantes latinoamericana.

\section{Migración y género: perspectiva teórica}

La migración se refiere teóricamente a un flujo de circulación asociado a la movilidad humana que se justifica y se motiva principalmente por situaciones económicas, políticas y/o humanitarias, dentro del cual los latinoamericanos han estado muy presentes. Se establecía normalmente que una corriente migratoria iba desde los países con mayor vulnerabilidad económica hacia los polos desarrollados, conceptualizado geográficamente como una migración "sur-norte" (Reysoo, 2004, 19). Sin embargo, como lo explica Carolina Stefoni $(2002,141)$ en la actualidad, "los tradicionales centros de atracción de la migración latinoamericana (Estados Unidos, España, Italia, Alemania) han comenzado a cerrar sus fronteras, diseñando políticas más restrictivas y de mayor control sobre la población migrante".

$\mathrm{Si}$ bien previamente, las migraciones latinoamericanas se 
caracterizaban por un movimiento "sur-norte" -es decir, desde un país en desarrollo hacia un polo desarrollado-, las restricciones de entradas hacia los tradicionales centro de atracción dentro de una economía globalizada provocaron un cambio que generó una nueva oleada migratoria de tipo intrarregional. Esto se define como sujetos migrantes trasladándose dentro de la misma región: los peruanos en Chile y los haitianos en República Dominicana, son unos ejemplos. Martínez Pizarro $(2003,22)$ conceptualiza este fenómeno como una migración intralatinoamericana justificando que los migrantes se encuentran focalizados en reorientar sus preferencias territoriales y encontrar países intermedios en la misma América Latina favorables y con oportunidades de trabajo.

Se puede insinuar entonces que las aberturas de los mercados internacionales incrementaron las desigualdades entre las diferentes economías mundiales causando nuevos ciclos migratorios y una nueva territorialidad atraída desde la oferta y demanda de los países económicamente más estables. Eso apunta a que primero, la globalización afecta de formas dispares las diferentes economías mundiales causando un movimiento migratorio distinto a la tradicionalnorte-sur, motivandoasíen América Latinaun movimiento sur-sur destinado a la oferta de empleos de baja calificación muchas veces dirigidas hacia las mujeres: trabajo doméstico, servicio, entre otros, involucrando entonces a la mujer dentro de la migración intrarregional latinoamericana, por los polos de atracción dentro de la región (Sassen, 2003a-b). Segundo, los movimientos migratorios se extienden, se modifican y cambian su territorialidad lo que permite "captar y movilizar las poblaciones numerosas y dispersas del mundo contemporáneo en formaciones étnicas trasnacionales" (Appudurai, 1999, 122). Es decir, la economía globalizada modifica la territorialidad de la migración afectando de forma diferente a los sujetos involucrados en estos tipos de movimientos: sea el origen y destino afecta diferentemente a cada migrante.

\section{Mujer y género}

El concepto de mujer por su parte, se introduce a raíz de un nuevo discurso académico: el estudio de género. Según Marta Lamas (1996), el género desde la matriz castellana no se construye alrededor 
de la taxonomía de lo femenino como "un concepto asociado con el estudio de las cosas relativas a las mujeres" (329) sino más bien desde la concepción y construcción del poder desde la diferencia de los sexos. Sería pues un mecanismo constructivo de las relaciones sociales fundamentadas en los contrastes que distancian los sexos. El género es entonces una forma elemental de relaciones características de poder.

Conjuntamente, esta perspectiva discursiva de género según Lamas (336) se construye simbólicamente y culturalmente desde una suma de prácticas, experiencias, pensamientos y discursos sobre la perspectiva de lo que debería ser lo masculino y lo femenino. Estas representaciones simbólicas son la base de la producción o fabricación del sujeto social, sus diferencias y la implicación de una jerarquización, subordinación y relaciones de poder. Es decir que, las mujeres y los hombres son el resultado de una producción histórica y cultural desde una dicotomía del dominador/dominado en un modo masculino/femenino. Se puede añadir que el género es una observación de los orígenes identitarios subjetivos entre hombres y mujeres.

\section{Conceptos migratorios y género}

\section{A) Lo diferencial del sexo}

La pauta teórica sobre lo diferencial del sexo ha introducido en alguna medida la temática alrededor de la migración y el género. Este concepto ha buscado demostrar que las principales teorías investigativas alrededor de las experiencias migratorias han sido construidas desde una masculinidad laboral. Se puede observar un fuerte androcentrismo en los estudios sobre migración hasta los años 80 por haber construido un marco teórico sobre la migración omitiendo el rol y la experiencia de la mujer dentro del proceso, basándose en la dicotomía producción/reproducción.

Bajo esta perspectiva, la investigadora Julia Eva Jiménez $(1998,7)$ apunta a que estas teorías presentaban al sujeto migrante desde un enfoque laboral y masculino, describiendo así a la mujer migrante como una simple acompañante. Para justificar este razonamiento, 
Jiménez analiza extensamente las diferencias de roles en las parejas, desde la dicotomía tradicional de producción/reproducción. La experiencia de la mujer no interesaba tanto a los académicos de estos tiempos ya que las teorías migratorias se construían en base a motivaciones laborales. En efecto, como las principales teorías estaban enfocadas en el ámbito económico, la mujer (desde su concepción tradicional) no encajaba dentro del conjunto analítico. Es decir, según esta forma de pensar, las mujeres al ser concebidas como no-trabajadoras, no tenían poder de decisión en la migración, entonces no eran incluidas dentro del enfoque analítico de investigación migratoria.

En este sentido, la teoría de lo diferencial del sexo que señala Jiménez, propone romper los moldes que interpretan la migración desde un punto de vista masculino, permitiéndoles a las mujeres una nueva visibilidad dentro del entramado migratorio. Esta teoría propone que la experiencia migratoria sea diferente entre sexos, además, pretende romper con la dicotomía entre producción/ reproducción. En este sentido, la migración no debe solamente analizarse desde el punto productivo ya que la experiencia migratoria se extiende a más y afecta a la mujer de diferentes formas que al hombre. Jiménez logra, a partir de esta teoría, evidenciar la necesidad de estudiar de forma más profunda la presencia de la mujer dentro de los movimientos migratorios para desarrollar un análisis sobre la construcción discriminatoria sufrida por ellas en los diferentes contextos migratorios.

\section{B) Feminización de la migración}

Es durante la década de los 80 donde se da un cierto giro en la percepción sobre el concepto del migrante. Gracias a la noción de lo diferencial del sexo expuesto por Jiménez, se inicia un nuevo término conceptual dentro del marco teórico migratorio, que implicó un cambio significativo y una cierta introducción de la mujer como nueva sujeta migrante. Bajo este contexto se empezó a desarrollar y justificar la conceptualización del término feminización de la migración. Dentro del argumento de la emergencia de las perspectivas feministas, se ha iniciado, en cierta medida, la desmitificación del rol de la migrante femenina incorporando el término género 
dentro de los estudios migratorios e introduciendo la noción de la feminización de la migración. Esto, pretendiendo definir y delimitar dos elementos introductores de este nuevo concepto. Primero un aspecto cuantitativo que subrayaba y evidenciaba un supuesto aumento numérico de mujeres dentro de las corrientes migratorias, posiblemente analizado desde la perspectiva globalizante de movilizaciones regionales, interregionales e internacionales ${ }^{7}$. En segundo lugar, el enfoque más fundamental, y en el cual se debe centrar, no pretende ser tanto el aumento sustancial de la migración femenina sino se enfoca en un perfil participativo de éstas como sujetas migrantes independientes, individuales en búsqueda de oportunidades laborales.

La reciente diversificación laboral producto de la economía neocapitalista les permitió a las mujeres migrar en búsqueda de nuevas oportunidades laborales sin ser obligadas a acompañar el movimiento migratorio masculino para validar su desplazamiento. Tal como lo afirma Reysoo (2004, 21) "la migración femenina se organiza según una restructuración de la economía global (...) la estructura de la migración ligada al trabajo cambió profundamente paralelamente a la nueva división internacional del trabajo y del papel económico creciente de la mujer".

Según Stefoni $(2002,120)$ las principales razones que justificarían la migración femenina serían de orden económico (si bien otros discursos apuntan hacia la emancipación y libertad personal). Aunque la feminización de la migración no se caracteriza de forma homóloga en todos los países, la región latinoamericana señala una predominancia a la migración femenina intrarregional ${ }^{8}$. Estos cambios se evidencian tanto en la toma de decisiones de las mujeres, como en su integración, transnacionalidad ${ }^{9}$ y el envío de remesas.

Vale la pena aclarar que, si bien los estudios académicos europeos empezaron a entender que la sujeta migrante representaba una entidad distinta a la del sujeto migrante masculino, con una experiencia diferente por su género, no obstante, la feminización de la migración debe necesariamente cruzarse con otras dimensiones como la perspectiva de género. Ésta, por sí sola, no permite explicar las diferencias migratorias padecidas por las mujeres migrantes: las discriminaciones e invisibilidades, por ejemplo. Es decir, el género y la migración se deben cruzar con la perspectiva de territorialidad, 
en este caso la intrarregionalidad, para enriquecer el análisis en los estudios migratorios desde un enfoque de género.

\section{C) Contrageografías de la globalización}

La socióloga holandesa Saskia Sassen (2003a, 1) manifiesta que la feminización de la migración se explica principalmente por los cambios definidos a raíz de las dinámicas de cambio estructural en la economía mundial globalizada. Se entiende la globalización como:

una tendencia histórica a la interrelación entre actores sociales geográficamente distantes y anteriormente no vinculado (...) hay una variedad infinita de actores y prácticas sociales, entonces ocurre que estas interconexiones históricamente resultan multidimensionales, es decir, involucran lo que suelen llamarse las dimensiones "económica", "política", "cultural" y "social" (Mato 2001, 131-132).

De forma simultánea, se transmite la representación de que la globalización está profundamente enlazada al incremento de la movilidad, y quela paulatinainterdependenciaeconómica y comercial se asocia a la acentuación de la migración internacional (Martínez Pizarro, 2002, 11). Sin embargo, tal como es acentuado por Stefoni $(2002,26)$, las migraciones latinoamericanas han debido redirigirse por las nuevas exigencias políticas y económicas de los países tradicionales de migraciones. Desde esta perspectiva, Sassen (2003b) observa la perspectiva feminista de la economía global relacionada a su geografía, lo que le permitió crear nuevos mecanismos que autorizaran un tipo de integración de la mujer a la fuerza del trabajo. Utilizó el concepto contrageografías de la globalización para describir estos circuitos transfronterizos generados desde la oferta de empleo internacional, que le han permitido a las mujeres incorporarse como migrantes en los diferentes tipos de trabajos ofrecidos -servicios domésticos, manufacturas, economía informal-10. Sin embargo, la misma globalización habría acrecentado y marcado la segmentación del mercado laboral, facilitando así los procesos de desvalorización y desigualdad de la mujer (2003b, 119), en otras palabras, creó "una 
clase de trabajadoras invisibles y desapoderadas en los servicios estratégicos que constituyen la economía global" (2003b, 123). Es decir, que la emancipación de las mujeres y la integración de ellas dentro del circuito migratorio internacional esconden una nueva tendencia que enlaza a dichas mujeres a ciertos tipos de abusos y vulnerabilidad.

\section{Invisibilidad, género y migración}

A raíz de esta amplia mirada conceptual teórica, se cree oportuno desarrollar una reflexión crítica delimitando la asociación entre género y migración intrarregional que permite incorporar la noción de la invisibilidad y así los factores que imposibilitan una mayor representación de la migrante latinoamericana en las observaciones teóricas migratorias. Se ha delimitado tres términos que permiten explicar la conexión entre invisibilidad, género y migración en la región latinoamericana: la mujer misma, su cuerpo y el mundo globalizado.

\section{A) La "mujer"}

¿El término mujer puede ser articulado a la relación entre invisibilidad, género y migración intraregional? Simone de Beauvoir en su libro Le deuxième sexe escrito en 1949, presenta la premisa teórica que introduce la base para este argumento. En este ensayo, fundador del pensamiento feminista presente, De Beauvoir define el término "mujer" como un producto histórico de construcción cultural, reglamentado por la educación y la socialización de las mujeres, y que ha llevado a definirlas siempre desde su rol de madre, esposa, hija y hermana. Para De Beauvoir la definición de lo que es ser mujer no revela en nada lo biológico, fisiológico o psicológico sino se interpreta desde las relaciones masculinas/femeninas de poder desde una perspectiva histórica. Así, la mujer se convierte en un objeto intercambiable dentro de la sociedad construida por hombres, lo que permite fomentar la supuesta creencia en la inferioridad de la mujer que la confina a roles maternales reproductivos y no productivos. De allí la famosa frase: "No se nace mujer: se llega a serlo" siendo la mujer una construcción histórica y no un hecho natural, biológico. 
De esta manera podemos decir que, mientras la mujer se define como una construcción histórica aprendida a raíz de la educación y la socialización de una posición patriarcal, el género -a partir de la definición hecha por Lamas (1996) - se centra históricamente en las relaciones de poder entre hombres y mujeres. En esta perspectiva de mujer y género es donde podemos reconocer la incorporación tardía de la perspectiva de género en los estudios migratorios.

Así mismo, la teoría de lo diferencial de sexo ha logrado en cierta medida introducir la relación entre género y migración a partir de lo cual se observó por consiguiente el concepto de feminización de la migración. Estos dos conceptos claves lograron relacionar y concluir que tanto la mujer como su experiencia migratoria han sido estudiadas desde la concepción tradicional de la "mujer", lo que permite entonces identificar nuevos roles y patrones desempeñados por ellas como sus potenciales discriminaciones padecidas a raíz de éstos, además de evidenciar la proporción cuantitativa de mujeres migrantes y la nueva independencia en cuanto a la forma de movilidad.

A pesar de estos avances conceptuales, las nociones tradicionales ya expuestas por De Beauvoir, frente a lo maternal, reproductivo y la supuesta inferioridad permitirían adelantar la mirada y los aspectos en los cuales enfocar para permitir una mejor perspectiva de las diferencias de género dentro de las migraciones y las consecuencias. Es decir, en cada aspecto de la migración, la mujer, por su construcción histórica y cultural además de su cuerpo reproductivo, vive la migración inevitablemente diferente que puede llevar a padecer discriminaciones que no afectan al sujeto migrante masculino. Por el supuesto individualismo de su movimiento migratorio esta sujeta puede verse implicada tanto en trata y tráfico de personas, maltrato, explotación laboral, como la no representatividad de sus derechos sexuales y de salud.

\section{B) El mundo globalizado}

En segundo lugar, en relación a lo ya evidenciado por Sassen (2003a-b), la rápida globalización y el clima variable de la economía mundial ha incorporado a las sujetas migrantes dentro de un flujo de circulación internacional controlado por la oferta y demanda 
de mano de obra -muchas veces- no calificada. La sujeta migrante simboliza entonces una nueva dinámica de movimiento que es controlada no tanto por una decisión personal si no por las necesidades de la economía internacional ${ }^{11}$. Es decir, las corrientes sur-sur globalizadas en la región han llevado a las mujeres a un mayor protagonismo. Por ejemplo, las ofertas laborales de baja calificación se han polarizados hacia una mano de obra femenina: sea una de servicio, servicio doméstico, manufacturas, entre otros.

Además, en estos casos, la definición de "mujer" -desde el punto de vista de De Beauvoir- se extiende a la manera en que ellas deben cumplir la doble función de producción/reproducción dentro del contexto de la globalización. Es decir, la economía global cambia e incorpora a la mujer dentro de nuevos roles que modifican los patrones sociales y culturales tradicionalmente aceptados en la región de América Latina. Tanto la velocidad a la cual se ha permutado estos cambios como la reciente incorporación de la perspectiva de género puede en cierto sentido evidenciar la relación entre invisibilidad, mujer y la migración. Esto justificado por la percepción y definición del concepto "mujer" dentro del imaginario colectivo latinoamericano que identifica nuevas consecuencias de estos cambios sobre estas nuevas sujetas. A raíz de este nuevo contexto global, la vulnerabilidad de la migrante latinoamericana se demuestra en los fenómenos alarmantes de trata y el tráfico de personas, maltrato y violencia además del no respeto de los derechos reproductivos y laborales.

Si bien se ha identificado dicha movilidad de la mujer en la globalización, los estudios e investigaciones que se han dedicado a este tema desde la perspectiva de Contrageografías de la globalización, se han centralizado en los tipos de trabajos no calificados desempeñados por la mujer, es decir, en el ámbito doméstico, de manufacturas, el cuidado infantil o trabajadoras sexuales. Este enfoque también amplía la percepción tanto de la definición de "mujer" como un ser inferior, una posición de silenciamiento por el tipo de trabajo efectuado y una vulnerabilidad como nueva sujeta productiva (Catarino y Morokvasic, 2008, 3). Además, desde la perspectiva globalizante, se insinúa que las mujeres integran solo estos movimientos migratorios haciendo trabajos de baja remuneración y calificación ${ }^{12}$. El enfoque desde esta percepción de la mujer laboral, trae consigo tanto un 
aspecto de vulnerabilidad como cierta tendencia a identificar a la mujer migrante desde la perspectiva de "inferioridad".

\section{C) Cuerpo}

Otro aspecto con el cual se puede asociar la invisibilidad con la migración y el género es desde la teoría de Judith Butler (1998). Ella instaura el concepto de "cuerpo" como materialidad organizada desde "actos performativos". Tomando los conceptos de de Beauvoir y Merleau-Ponty, Butler precisa que el cuerpo sería un "proceso activo de encarnación de ciertas posibilidades culturales e históricas" (298). Es decir, obliga a la representación del cuerpo femenino a convertirse en un símbolo histórico de "mujer". Desde esta perspectiva se crea una definición de género ya no como un hecho sino como una construcción imaginaria de los cuerpos, los cuales actúan desde una conformidad general que los lleva a personificar, promover y mantener una ficción cultural de división de género. Este cuerpo sería entonces encerrado en una apariencia del género establecida por actos históricamente dictados por una "repetición estilizada" (297) que asume el cuerpo sexuado. Es desde ahí que el cuerpo y la definición de mujer se pueden asociar a la personificación de una entidad inferior dentro del cual los actos performativos de la migrante pueden ser referidos a la invisibilidad y el silenciamiento.

En este sentido, la mujer latina como migrante cambia la dicotomía producción/reproducción asociada a lo masculino/ femenino, cambia así la definición de su "cuerpo" incorporando tantos roles productivos a consecuencia de la migración, como reproductivos. Es decir, rompe con los esquemas simbólicos e históricos de la mujer, determinados a partir de la crítica expuesta por de Beauvoir. La ficción de la división de género, en este contexto, es entonces minimizada culturalmente y la representación de esta sujeta como entidad inferior puede ser cuestionada a partir de su nuevo rol económico. A pesar de esta diferenciación en la definición como sujeta y los roles dicotómicos efectuados por la sujeta, el hecho de que el cuerpo de la mujer esté rompiendo la "repetición estilizada" históricamente establecida impone un cambio que subordina en cierto sentido a la mujer. Además, podría conducir a 
la vulnerabilidad de ésta. Es decir, la fragmentación del "cuerpo" de esta sujeta en dos representatividades desde la dicotomía establecida puede evidenciar nuevos cambios de no-representatividad. El cambio social que provoca la migración independiente de la mujer latinoamericana rompe con la imagen simbólica del cuerpo de ellas, esto puede llegar a vulnerarlas ya que permite fragmentar este entramado simbólico para incluir nuevos roles. Éstos incorporan nuevas representaciones figurativas del cuerpo de la mujer migrante en un contexto mundial apoderado por lo económico, tal como muestra Sassen (2003a-b), ya sea en la trata de personas, el comercio sexual $\mathrm{u}$ otros.

\section{Observaciones}

Incluir el tema de género al momento de estudiar las migraciones intrarregionales latinoamericanas es pertinente en la medida en que las perspectivas y el análisis migratorios demuestran la disparidad $\mathrm{y}$ la heterogeneidad entre los sujetos migrantes femeninos $\mathrm{y}$ masculinos. No obstante, y como lo muestra Boyd y Grieco (2003, 3) en relación a la perspectiva de género, y sabiendo que ésta es construida socialmente, su representación está sujeta a los flujos y movimientos poblacionales consecuencias de las economías mundiales. Esto significa que el género es variable y permutable en la medida en que se generen intercambios entre las diferentes sociedades consecuencia de la territorialidad. Lo mismo puede ser insinuado en relación a los términos "mujer" y "cuerpo" en una matriz migrante teorizada por de Beauvoir y Butler. Es decir, estos términos, a raíz de la feminización de la migración y los nuevos roles de las mujeres dentro de las migraciones imponen un nuevo tipo de vulnerabilidad al ser insertados en ambas partes de la dicotomía.

A raíz de esta observación, ¿cuáles son entonces los factores que imposibilitan una mayor representación de la migrante latinoamericana en las observaciones teóricas migratorias regionales? Varios investigadores apuntan a que es tangible asociar esta problemática a la constante necesidad de justificar a la sujeta migrante femenina como tema des estudio, es decir, el motivo por el cual estudiar la mujer migrante. Pues, la mayoría de las investigaciones dirigidas a ampliar el análisis de la migración 
femenina pretenden, en primera instancia, subrayar estadísticas y conceptos que diferencien los sexos, el sex ratio o la feminización de la migración para demostrar la necesidad de ampliar los estudios sobre mujeres migrantes. Sin embargo, ninguna investigación sobre migración masculina tendrá la pretensión de exponer este tipo de elementos y estadísticas (Catarino y Morokvasic, 2008).

Ser incorporada en los movimientos migratorios intrarregionales latinoamericanos a raíces de los cambios económicos globalizados, ha permitido a las mujeres, en cierto sentido, modificar, los patrones sociales y culturales en la región. Sin embargo, la velocidad en la cual la migrante ha transformado la representación simbólica de su cuerpo como el significado imaginativo de la terminología "mujer" tiene como consecuencia su poca representatividad ya que adquiere dos representatividades dicotómicas desde lo productivo/ reproductivo. Además, en cada aspecto de la migración, la mujer, por su construcción histórica y cultural de su cuerpo reproductivo, vive la migración inevitablemente diferente que puede llevar a padecer discriminaciones que no afectan al sujeto migrante masculino.

Ya que, a pesar de que los años 80 en algún sentidos abrieron una nueva línea de pensamiento desde la perspectiva de género, con lo diferencial de sexo y la feminización de la migración, la velocidad con la cual los movimientos migratorios se han desarrollado, a partir de la globalización económica, han incorporados varios sujetos en un estado de silenciamiento que simplemente no han sido evidenciados. El género como el concepto de lo diferencial del sexo ${ }^{13}$ obliga a poner en perspectiva cada teoría y posición para observar de forma nueva un acontecimiento y así incorporar el tema de la mujer, y en este caso de la sujeta migrante. Es decir que, las transformaciones apresuradas a raíz del clima global imponen nuevos patrones identitarios poco estudiados y entonces silenciados. Las mujeres migrantes son nuevas sujetas intrarregionales en América Latina que deben entonces ser integradas dentro de estas nuevas pautas analíticas y estudiadas con un mayor enfoque hacia los cambios rápidos dentro del esquema globalizado y los cambios eminentes que influencia la mujer al ser objeto de migración independiente.

Los flujos migratorios internacionales se modificaron a raíz de las nuevas exigencias políticas y legales de los países en desarrollo tal como explicado por Stefoni $(2002,141)$ lo que ha causado un giro 
en los movimientos: pasaron de sur-norte a sur-sur. Este añadido conceptual -sea el carácter intrarregional y su territorialidadincrementa las perspectivas que añadir y considerar al momento de analizar la migración femenina latinoamericana y lo que puede obstaculizar un análisis pertinente de todas las facetas que implica la migración femenina en la región. Pues, la velocidad de los cambios económicos mundiales y su territorialidad han generado circuitos migratorios intrarregionales que esconden nuevas tendencias que enlazan a las sujetas mujeres a ciertos tipos de abusos y vulnerabilidad; trata y tráfico de personas, maltrato, explotación laboral, como la no representatividad de sus derechos sexuales y de salud.

Para entender lo que vehicula a estas sujetas migrantes a estos tipos de abusos y vulnerabilidades, se debe entonces considerar, además del carácter económico, la territorialidad desde la perspectiva de género en América Latina; es decir, confrontar los diferentes motives que llevan a las migrantes a padecer estos tipos de abusos específicos. Dentro de la región se debe permitir conjuntamente más análisis comparativos para observar las pautas y las discordancias entre los países de la región para así obtener un cuadro de la sujeta migrante más específico a la región. También, al analizar la territorialidad y comparar las similitudes y discordancias entre países latinoamericanos, se debe también analizar, por ejemplo, conjuntamente el origen/destino, la legalidad/ilegalidad de los movimientos, sus diferentes tipos de incorporación laborales para lograr entender las transformaciones de la mujer migrante, la representación simbólica de su cuerpo dentro de las observaciones teóricas migratorias regionales, los abusos y las vulnerabilidades padecidas.

\section{Conclusiones}

Los conceptos de mujer, género y cuerpo en el mundo globalizado han creado y evidenciado varias vulnerabilidades padecidas por ellas - la trata de persona, el comercio sexual u otros- que se deben investigar más para conocer con mayor certeza la amplitud del problema. Es decir, la invisibilidad de ellas también tiene que ver con la incapacidad definir de forma concreta y específica los cambios 
sociales y territoriales que les afectan, perjudican o que permutan la realidad de la migrante mujer latinoamericana. Con una ampliación de estudios académicos sobre este nuevo sujeto migratorio, se permitiría tanto conocer las nuevas circunstancias afectando a la mujer migrante para entonces mitigarlas y reducirlas con evidencias y estadísticas claras que permitirían desarrollar políticas públicas en los diferentes polos latinoamericanos receptores de migrantes femeninas para la visibilidad de estos sujetos.

En conclusión, se evidencia que el factor predominante que debilita una mejor representación de la migrante latinoamericana en las teóricas migratorias regionales sería la dificultad de analizar conjuntamente las diferentes componentes que califican a la experiencia migratoria femenina: el género, el cuerpo, la territorialidad y las consecuencias dela globalización. La invisibilidad de la migrante latinoamericana se relaciona entonces con este límite analítico. Se necesita por lo tanto un enfoque y un compromiso verdadero hacia el estudio de la mujer migrante latinoamericana dentro de los diferentes contextos intrarregionales y nacionales para visibilizar y disminuir la vulnerabilidad y discriminación de este sujeto migrante. De esto, también tener una perspectiva clara de los flujos migratorios femeninos en la región para poder desarrollar políticas públicas de integración que respetan los derechos específicos a la mujer.

\section{Notas}

1. Fuente tomada de Zlotnik, 2003 por Martínez Pizarro.

2. La utilización del término sujeta en vez de sujeto o sujeto femenino es justificado por la necesidad de incorporar dentro de los estudios de Género un vocabulario específico a la mujer.

3. Jiménez $(1998,8)$ revela que las investigaciones anteriores a los años 80 no se enfocaban en el tema del género, lo que podría señalar un escaso interés y relevancia en el tema por parte de la comunidad científica. Referirse, entre tantos ejemplos presentados por Jiménez a Everett Lee (1966), Harris y Todaro (1970) y Wilbur Zelinsky (1971).

4. Según José Itzingsohnl (2003, 79) las políticas neoliberales son una de las causas del el aumento de las migraciones. Si bien la urbanización fue un elemento significativo de la industrialización, sea de la fase económica anterior; "el marcado aumento 
de la pobreza, el deterioro de las condiciones de empleo y la incapacidad de las nuevas democracias para responder a los reclamos sociales de la gente, han hecho que la migración internacional se transforme en una estrategia de subsistencia y movilidad social". Estas observaciones analizadas teóricamente desde un ámbito económico (producción/reproducción), sea desde lo masculino.

5. Como las migraciones internacionales eran caracterizadas por ser de tipo masculinas, las mujeres que migraban de forma independiente antes de los años 80, sea por razones laborales, económicas u otras, se veían incorporadas o asociadas a la experiencia de los hombres. Es decir, se pretendía que los modos y cambios eran iguales por ser de carácter laboral. Entonces, no se buscaba evidenciar las diferencias por sexo vividas en el proceso de migración, adaptación, etc. por el hecho de ser mujer. Para mayor información ver (Szasz, 1999 y Hugo 1991).

6. Es decir, la salida hacia un país desarrollado (sur-norte) es inevitablemente disímil a la experiencia migratoria intrarregional latinoamericana (sur-sur) motivada por mecanismos transfronterizos generados desde la oferta de empleo internacional que puede acrecentar la segmentación del mercado laboral hacia las mujeres.

7. Una estadística pertinente que mencionar, en la década de los 80 , las mujeres migrantes latinoamericanas fueron las primeras del mundo en desarrollo en alcanzar el porcentaje de los hombres migrantes, llegando a representar $50 \%$ de las migraciones de dicha región (Naciones Unidas: 2009, 5). Sin embargo, se debe relativizar un poco este carácter cuantitativo de la feminización de la migración. Se puede afirmar que los desplazamientos, sí aumentaron y que sus características han tomado diferentes aspectos, sin embargo, tal como lo pretende Flores Cruz (sin fecha: 3), estos no pueden compararse a las movilidades rural-urbano durante la Revolución Industrial o a los movimientos migratorios ultramarinos de finales del siglo XIX y principio del siglo XX.

8. Se puede enfocar en el fenómeno de la feminización de la migración desde una perspectiva intrarregional a modo de ejemplo con la migración femenina haitiana hacia República Dominicana. Si inicialmente la migrante femenina era invisible dentro de los bateyes al asociarse sólo como sujeto acompañante masculino, luego de los cambios como consecuencia de la urbanización de la migración se introduce a la haitiana dentro de esta corriente compleja y heterogénea, incorporándola como nueva sujeta de la migración. La diversificación laboral le permitió entonces a la haitiana migrar de forma más independiente, en búsqueda de nuevas oportunidades laborales sin la obligación de acompañar el movimiento migrante masculino para validar su desplazamiento. Dentro de un contexto cada vez más globalizado se ha permitido presenciar y observar tanto el aumento cuantitativo de la feminización de la migración haitiana y el carácter autónomo e individual que tomó la mujer al momento de marcharse hacia el país vecino. Además, el espacio laboral de la mujer haitiana en República Dominicana se ha centrado en una esfera diferente a la de los hombres, sea en el comercio informal y los servicios domésticos a contrario de 
los migrantes masculinos que se centran más dentro de la construcción (Wooding, Moseley-Williams, 2004).

9. Si antes se vivía con un núcleo familiar extenso: padres, abuelos, tíos, etc. - ahora, las nuevas realidades migratorias crean el concepto de la transnacionalidad. Este término reciente nace de la idea de migraciones transnacionales, el que se define como "un fenómeno dentro del cual los migrantes mantienen y promueven relaciones entre el país donde residen, su tierra natal y comunidades locales" (Mahler y Ugrina, 2006, 11, cita traducida libremente del inglés).

10. Las mujeres migrantes peruanas hacia Chile podrían ejemplificar de forma adecuada bien el concepto desarrollado por Sassen. En efecto, estas sujetas migrantes son las únicas a nivel intrarregional en Chile a exceder en porcentaje a sus compatriotas masculinos (Stefoni, 2002, 126). La feminización de la migración peruana en Chile se puede argumentar y justificar de varias formas. En primer lugar, las mujeres chilenas sureñas, asalariadas tradicionalmente relacionadas con el servicio doméstico, han gradualmente abandonado este tipo de empleo facilitando así las condiciones de mercado laborales para las migrantes peruanas en Chile para trabajar en este sector específico de la economía (Stefoni, 2002, 135). Es decir, la decisión de partir e integrar el movimiento puede ser entonces, el resultado de una decisión familiar, sea algo forzado, y que la mujer sea "elegida" como migrante como la economía global ha introducido necesidades de mano de obra barata encabezada por el trabajo jornalero de mujeres.

11. Dentro de los numerosos casos de esta realidad en América Latina se encuentra además de los casos expuestos, las mujeres mexicanas trabajando en las maquiladoras (ver Barajas, Martínez),

12. De esto, se olvida o minimiza la presencia femenina dentro de las corrientes migratorias como profesionales clasificadas, es decir, mujeres latinoamericanas incorporándose en un mundo laboral competitivo e internacional.

13. Se reitere que lo diferencial de sexo permite romper los moldes analíticos que interpretan la migración desde el punto de vista masculino. Esta teoría propone entonces una experiencia migratoria diferente entre sexos, además, pretende romper con la dicotomía entre producción/reproducción.

\section{Bibliografía}

Appudurai, Arjun. "Soberanía sin territorialidad: Notas para una geografía posnacional". Nueva Sociedad, 163 (Sep.-Oct.), 1999, 109-124.

Beauvoir, Simone de. Le deuxième sexe. Paris: Gallimard. 1949.

Boyd, Mónica y Elizabeth Grieco. "Women and Migration: Incorporating Gender into International Migration Theory", 2003. Consultado en junio 2011, http:// www.migrationinformation.org/Feature/display.cfm?ID=106

Butler, Judith. "Actos performativos y constitución del género: Un ensayo sobre fenomenología y teoría Feminista". Debates femeninos, 18, 1998, 296-314. 
Catarino, Christine y Mirjana Morokvasic. "Femmes, genre, migration et mobilités". Revue européenne des migrations internationales [En ligne], vol. 21 - n¹, 2005, consultado el 22 de septiembre 2008. http://remi.revues.org/2534

Flores Cruz, Ramiro. "La migración femenina en América latina”. Instituto de investigación Gino Germani, s/f.

Itzingsohn, José. "Migración, Globalización y Geopolítica" Anuario Social y Político de América Latina y el Caribe Nro. 6, Flacso / Unesco / Nueva Sociedad, Caracas, 2003, 77-82.

Jiménez, Juliá Eva. “Una revisión crítica de las teorías migratorias desde la perspectiva del género". Estudios Migratorios. N. 5, (1998): sin número de página.

Lamas, Marta. “Usos, dificultades y posibilidades de la categoría de género". En El género y la construcción cultural de la diferencia sexual. México: UNAM, 1996.

Mahler, S. y Dusan, U. "Central América: Crossroads of the Américas". Migration information Source. Abril (2006): 3-15.

Martínez Pizarro, Jorge. El mapa migratorio en América Latina y el Caribe, las mujeres y el género. Santiago, Chile: Proyecto regional de población CELADE, 2003.

Mato, Daniel. "Producción transnacional de representaciones sociales y transformaciones sociales en tiempos de globalización". En Daniel Mato (comp.) Estudios Latinoamericanos sobre globalización, cultura y transformaciones sociales. Buenos Aires: Consejo Latinoamericano de Ciencias Sociales-CLACSO, 2001.

Reysoo F. "Féminisation de la migration". En F. Reysoo y Ch. Verschuur (dir.). Femmes en mouvement : genre, migrations et nouvelle division internationale $d u$ travail. Berne, Commission suisse pour l'UNESCO; Direction du développement et de la coopération. Genève: Institut universitaire d'études du développement, 17-27, 2004.

Sassen, Saskia. "Contrageografías de la globalización: la feminización de la supervivencia". En Contrageografías de la globalización. Género y ciudadanía en los circuitos transfronterizos. Madrid: Traficantes de sueños, 2003a.

------. Los espectros de la globalización. Buenos Aires: Fundo de cultura económica, 2003b.

Stefoni, Carolina. "Mujeres inmigrantes peruanas en Chile". Papel de población. Julio-septiembre N³3, 118-145, 2002.

Wooding, Bridget y Richard Moseley-Williams. Inmigrantes haitianos y dominicanos de ascendencia haitiana en la República Dominicana. Santo Domingo: Cooperación Internacional para el Desarrollo (CID) y el Servicio Jesuita a Refugiados y Migrantes (SJR), 2004. 